\title{
Directional cloverleaf antenna for unmanned aerial vehicle (UAV) application
}

\author{
M. S. Safaron ${ }^{1}$, H. A. Majid ${ }^{2}$, B. A. F. Esmail ${ }^{3}$, A. S. Ab Ghafar ${ }^{4}$, F. A. Saparudin ${ }^{5}$, \\ M. F. Ismail ${ }^{6}$, M. A. Abdullah ${ }^{7}$ \\ 1,2,3,4,5,6 Faculty of Engineering Technology, Universiti Tun Hussein Onn Malaysia, Malaysia \\ ${ }^{7}$ Faculty of Electrical Engineering, Universiti Teknologi Malaysia, Malaysia
}

\section{Article Info}

Article history:

Received Sep 24, 2018

Revised Nov 25, 2018

Accepted Dec 9, 2018

\section{Keywords:}

$2.45 \mathrm{GHz}$

Cloverleaf antenna

Directional radiation pattern

Drone

Unmanned aerial vehicle

\begin{abstract}
3-blade and 4-blade cloverleaf antennas operating at $2.45 \mathrm{GHz}$ have been proposed. In order to achieve directional radiation pattern and high gain, reflector is incorporated to the proposed antennas. The proposed antennas have an average gain of $2.37 \mathrm{dBi}$ while the proposed antennas with reflector have an average gain of $6.38 \mathrm{dBi}$. The dimension of the proposed antenna is compact enough to be mounted on an unmanned aerial vehicle (UAV). Simulated and measured results are used to demonstrate the performance of the antenna. The simulated and measured return losses, together with the simulated radiation patterns, are presented and compared.
\end{abstract}

Copyright $(0) 2019$ Institute of Advanced Engineering and Science. All rights reserved.

\section{Corresponding Author:}

Huda A Majid,

Faculty of Engineering Technology,

Universiti Tun Hussein Onn Malaysia,

86400 Parit Raja, Batu Pahat, Johor, Malaysia.

Email:mhuda@uthm.edu.my

\section{INTRODUCTION}

Technology nowadays have made everything become light and compact, and it is also applied to Unmanned Aerial Vehicle (UAV). An Unmanned Aerial Vehicle (UAV), commonly known as a drone or unmanned aircraft system (UAS) is an aircraft without a human pilot aboard. The flight of UAV's may be controlled by various kind of methods, either by a given degree of remote control from an operator located on the ground or in another vehicle or fully autonomously using on board computer. UAV is required to establish several links for communications such as telemetry, tele-command or GPS, and in order to do so, UAV needs antennas to receive and transmit those different signals to communicate. The antennas used in UAVs must have small form factor and lightweight, where it does not affect the UAV aerodynamic characteristics and at the same time, improve the power management efficiency by providing such high gain and directional radiation pattern. Antenna technology for unmanned aerial vehicle has been developed rapidly according to the world aviation and aircraft demand. There are many types of antennas with different specification that can meet the aircraft ability and requirements.

A compact and lightweight microstrip patch antenna is preferred and used in radar system and unmanned aerial vehicle as proposed in [1]-[5]. Research in [6]-[10], states that several criteria should be considered as parameter for the antenna such as its mechanical or thermal stability, frequency, bandwidth, antenna radiation pattern, and easy integration into UAV structure. Based on research done by H. Jairam [11], a novel blade antenna has been designed to operate at $2.8 \mathrm{GHz}$ frequency. The results stated that the return loss is $-10 \mathrm{~dB}$ over the $4 \%$ bandwidth and the radiation pattern is tilted away from normal direction of propagation by $30^{\circ}$. It is necessary to dynamically steer the radiation pattern of the antennas for a best quality 
of service, avoid interference, secure system, proper coverage and power saving. A research in [12] proposed a fan blade shaped antenna for wideband circular polarization. The antenna has a $3 \mathrm{~dB}$ axial ratio bandwidth from 2.41-2.49 GHz resonant frequency. A bi-quad antenna is proposed for a long range surveillance system with a frequency range of $433 \mathrm{MHz}$ to $435 \mathrm{MHz}$ in [13]. However, 3D structure increase the complexity and size of incorporating the bi-quad antenna in the UAV system. In [14], a wideband waveguide and horn antenna using 3D printing technology is presented. The antenna structure covering $7.5 \mathrm{GHz}$ to $18 \mathrm{GHz}$ is embedded in the UAV wing. Meanwhile, a wideband low profile planar antenna for UAV application has been proposed in [15]-[17]. The cloverleaf antenna is likely the best over other choices to incorporate into the UAV system because of its compact size, low profile structure, inexpensive material and ease of mounting on the UAV system. In addition, the high gain and direction radiation pattern enhance the communication reliability and reduce the free space loss in the radio link between UAV and ground station.

In this paper, cloverleaf antennas with a different number of blades are analyzed, and their results are presented. 3-blade and 4-blade cloverleaf antennas operate at $2.45 \mathrm{GHz}$ and FR4 is used as the material to fabricate the proposed antennas to achieve compactness and lightweight. Furthermore, the directional radiation pattern is achieved by incorporating a reflector to avoid interference, secure system, proper coverage and power saving. Moreover, the gain is enhanced by $4.01 \mathrm{dBi}$ thereby the free space path loss can be alleviated. Consequently, the proposed antenna is suitable to be placed underneath an unmanned aerial vehicle (UAV) for optimizing the communication between the UAV and the ground stations.

\section{ANTENNA DESIGN}

Two types of cloverleaf antenna design have been proposed. The first design is 3-blade cloverleaf antenna and the second design is 4-blade cloverleaf antenna. Figure 1 and Figure 2 illustrates the geometry of 3-blade and 4-blade cloverleaf antenna, respectively. In addition, the dimension of both proposed antennas are tabulated in Table 1. The FR4 material is chosen due to its rigid structure and inexpensive. The thickness of the FR4 material is $1.6 \mathrm{~mm}$ while for the transmission line and antenna blade has a thickness of $0.035 \mathrm{~mm}$. The FR4 material has dielectric permittivity of 4.3 with tangential loss of 0.019 . Each blade of the cloverleaf antenna has an approximate length of $1 \lambda_{\mathrm{o}}\left(\lambda_{\mathrm{o}}=a+b+g\right)$ at $2.45 \mathrm{GHz}$. Via is used to connect the front and back blade. The front circular patch and the ground plane circular patch are optimized to get the best return loss possible.

Furthermore, both proposed antennas are incorporated with a reflector in order to obtain directional radiation pattern. The reflector is placed in such a way that is facing the ground plane of the proposed antenna. The gap between the proposed antenna and the reflector is $28.4 \mathrm{~mm}$ which is approximately $\lambda_{\mathrm{o}} / 4$ at the frequency of $2.45 \mathrm{GHz}$. The radius of the reflectors for both proposed antennas are $80 \mathrm{~mm}$. The fabricated proposed antennas are illustrated in Figure 3.

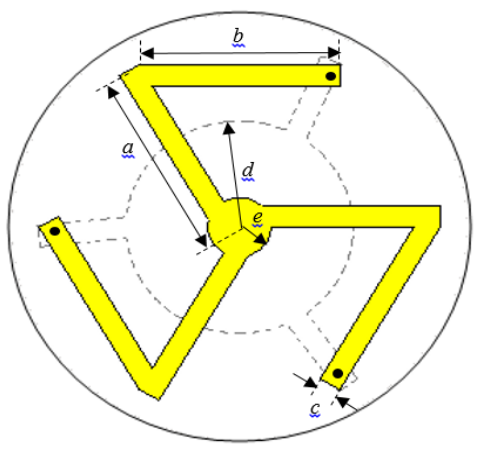

(a)

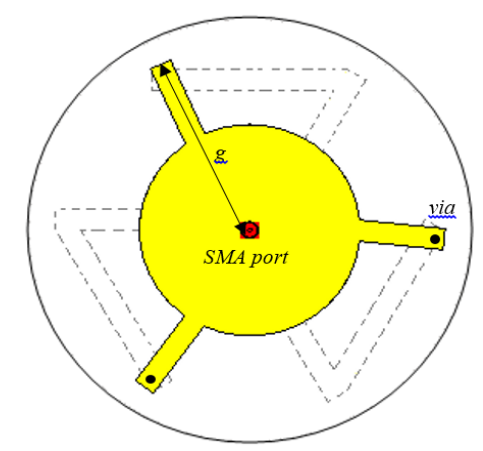

(b)

Figure 1. Geometry of 3-blade cloverleaf antenna (a) front view and (b) back view

Table 1. Dimension of the Proposed Antenna

\begin{tabular}{ccc}
\hline Parameter & 3-blade cloverleaf antenna $(\mathrm{mm})$ & 4-blade cloverleaf antenna $(\mathrm{mm})$ \\
\hline$a$ & 44 & 40 \\
$b$ & 44 & 40 \\
$c$ & 5 & 3 \\
$d$ & 25 & 25 \\
$e$ & 7 & 11 \\
$g$ & 44 & 40
\end{tabular}

Indonesian J Elec Eng \& Comp Sci, Vol. 14, No. 2, May 2019 : 773 - 779 


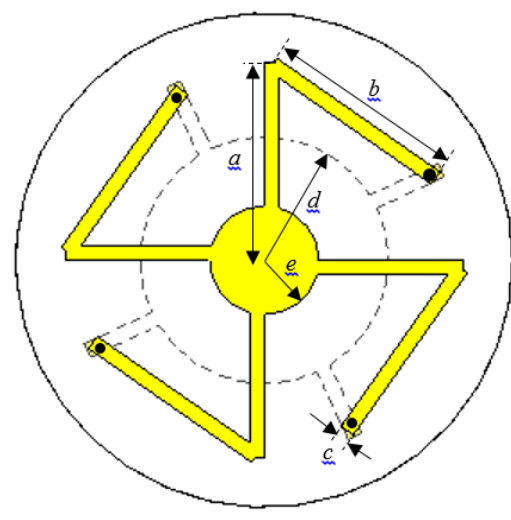

(a)

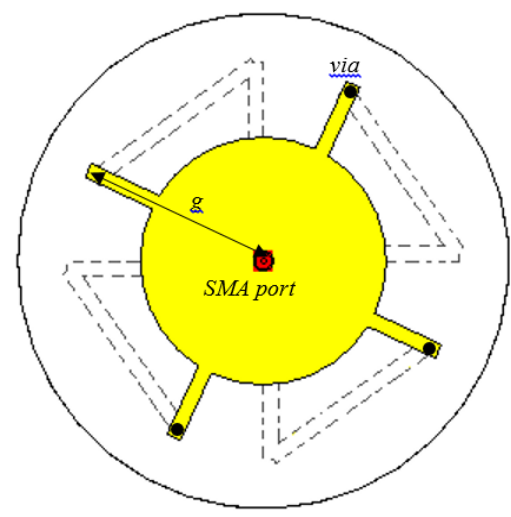

(b)

Figure 2. Geometry of 4-blade cloverleaf antenna (a) front view and (b) back view

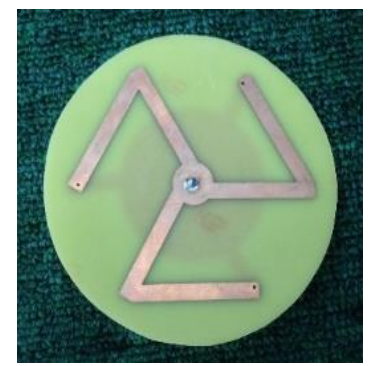

(a)

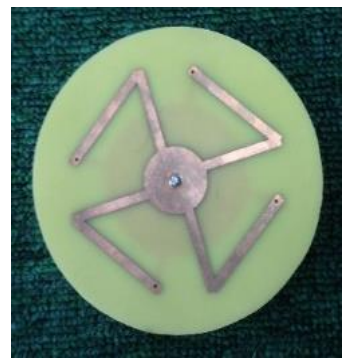

(b)

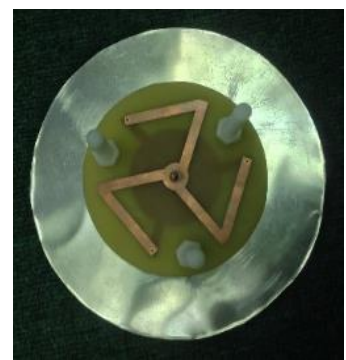

(c)

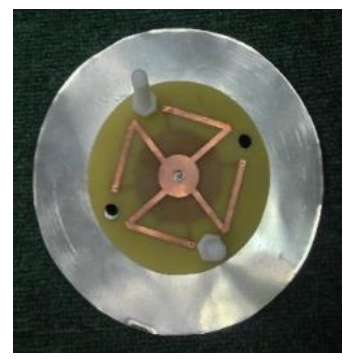

(d)

Figure 3. Fabricated proposed antennas where (a) 3-blade cloverleaf antenna, (b) 4-blade cloverleaf antenna, (c) 3-blade cloverleaf antenna with reflector and (d) 4-blade cloverleaf antenna with reflector

\section{RESULTS AND DISCUSSION}

The results are compared between the simulation results obtained using the CST software and the measurement results obtained from the vector network analyzer. The simulated and measured return losses for the proposed antennas are shown in Figure 4 to Figure 7. Figure 4 shows the return loss of the 3-blade cloverleaf antenna while Figure 5 shows the 4-blade cloverleaf antenna. In addition, Figure 6 and Figure 7 show the results of return loss of 3-blade cloverleaf antenna with reflector and 4-blade cloverleaf antenna with reflector, respectively. The simulated and measured return losses are less than $-10 \mathrm{~dB}$ for all proposed antennas. The measured resonant frequency of all proposed antennas are shifted to the higher frequency region with an average shift of $100 \mathrm{MHz}$. This is due to the inconsistency of the FR4 material permittivity value.

The simulated radiation patterns of all proposed antennas are shown in Figure 8 to Figure 11. The radiation patterns of 3-blade and 4-blade cloverleaf antennas are considered as near to omni-directional while the 3-blade and 4-blade cloverleaf antennas with reflector has directional radiation pattern. 3-blade and 4-blade cloverleaf antenna has a gain of $2.643 \mathrm{dBi}$ and $2.096 \mathrm{dBi}$ respectively. However, the 3-blade and 4blade cloverleaf antenna with reflector has higher gain which is $6.474 \mathrm{dBi}$ and $6.297 \mathrm{dBi}$ respectively. The 3D radiation patterns for all proposed antennas are illustrated in Figure 12. As observed, the proposed antenna with reflector has higher gain and directional radiation pattern which is suitable for UAV. The proposed antenna is recommended to be mounted underneath the UAV for better coverage between the UAV and ground station. The UAV is a movable object and this leads to different angles that built with ground stations, thereby the steering of the antenna's main beam is very important to adapt with moving of the UAV. However, this design provides fixed beam switching angle and this issue can be solved by embedded switching devices such as (PIN diodes or Varactor diodes) to continues steer the main beam of the cloverleaf antenna 


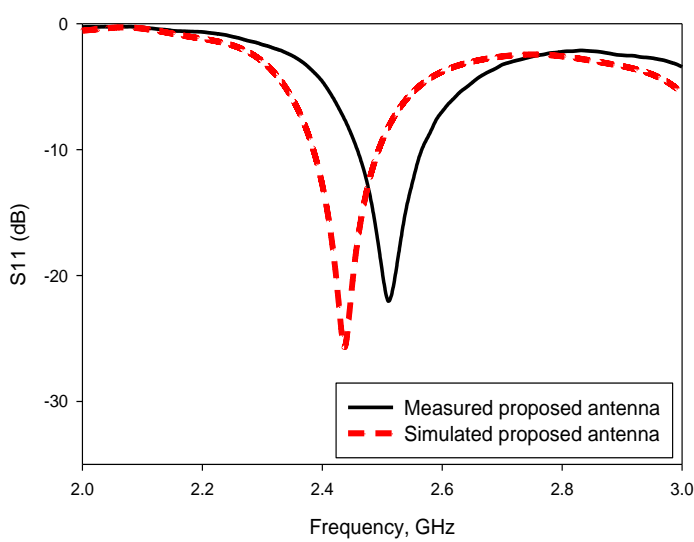

Figure 4. Measured and simulated reflection coefficient of 3-blade cloverleaf antenna

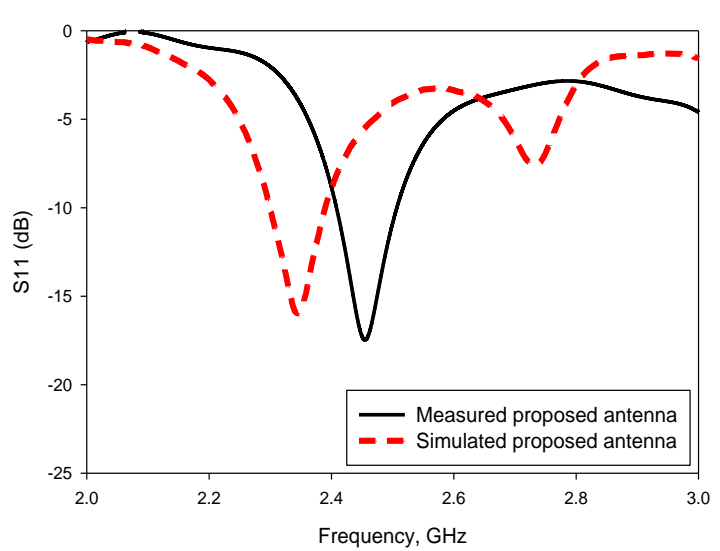

Figure 6. Measured and simulated reflection coefficient of 3-blade cloverleaf antenna with reflector

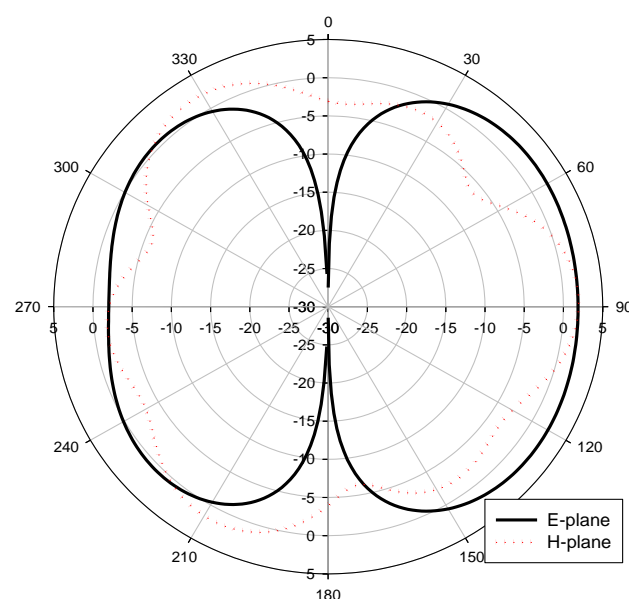

Figure 8. Simulated radiation patterns of 3blade cloverleaf antenna

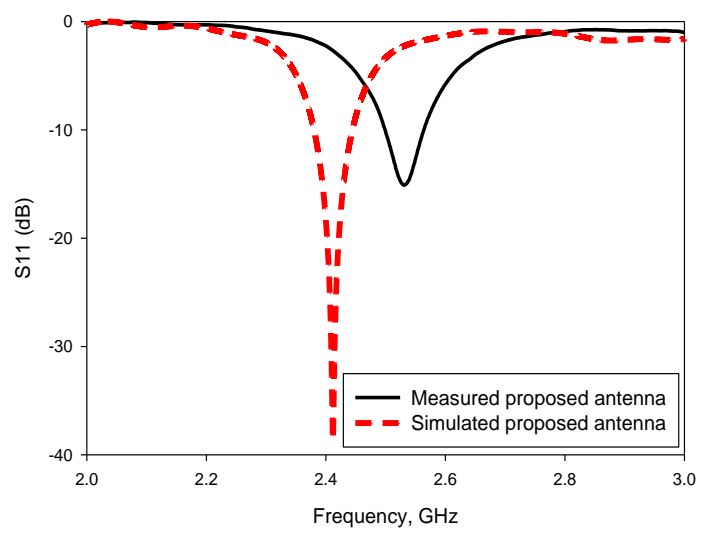

Figure 5. Measured and simulated reflection coefficient of 4-blade cloverleaf antenna

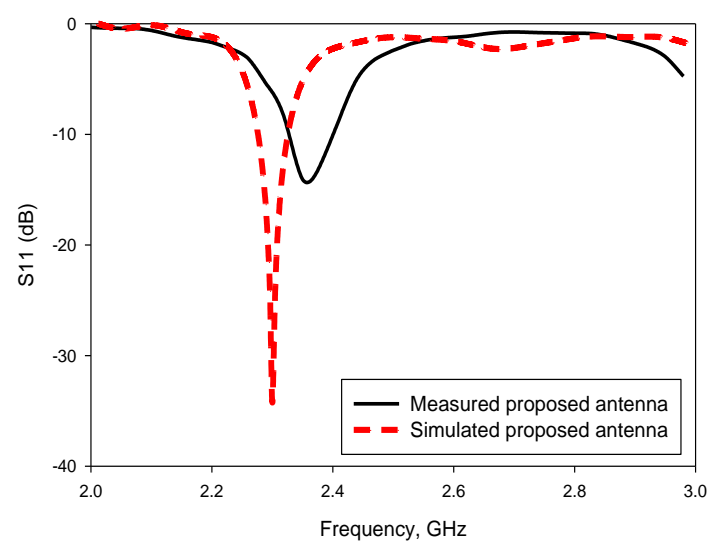

Figure 7. Measured and simulated reflection coefficient of 4-blade cloverleaf antenna with reflector

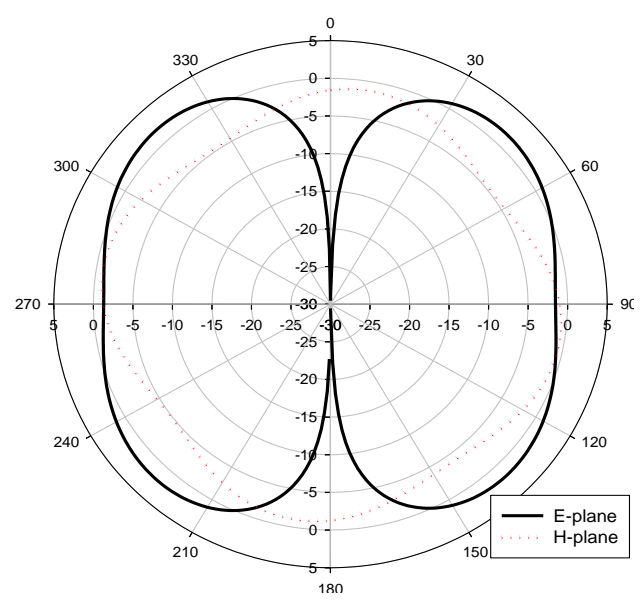

Figure 9. Simulated radiation patterns of 4blade cloverleaf antenna 


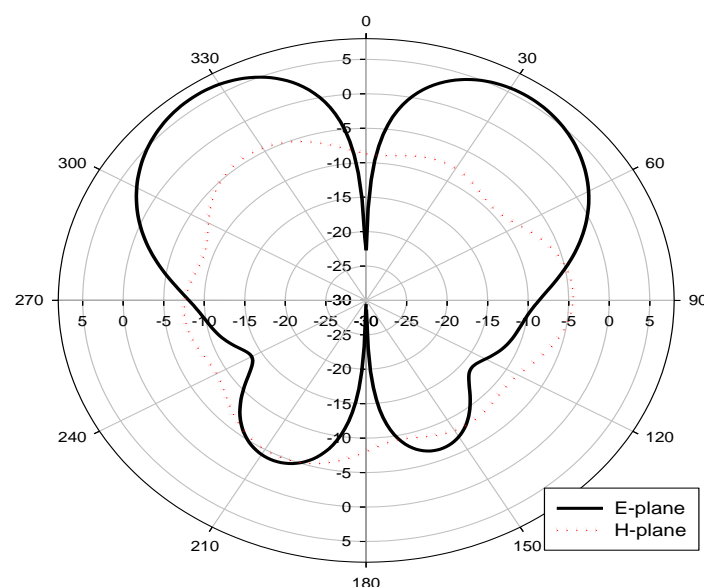

Figure 10. Simulated radiation patterns of 3blade cloverleaf antenna with reflector

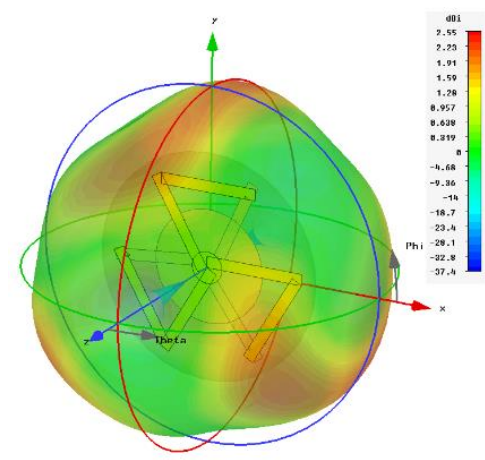

(a)

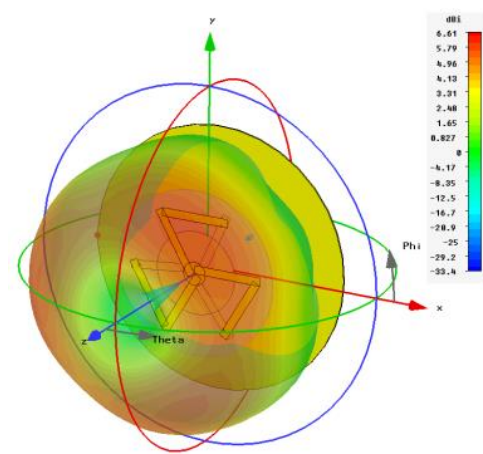

(c)

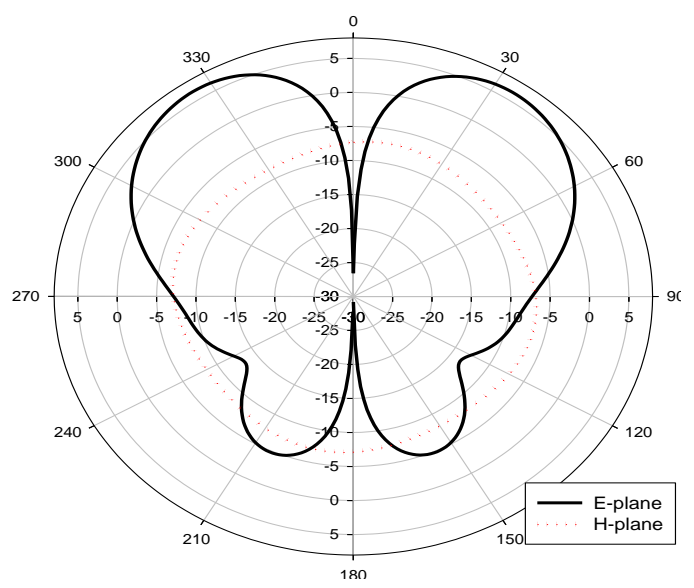

Figure 11. Simulated radiation patterns of 4-blade cloverleaf antenna with reflector

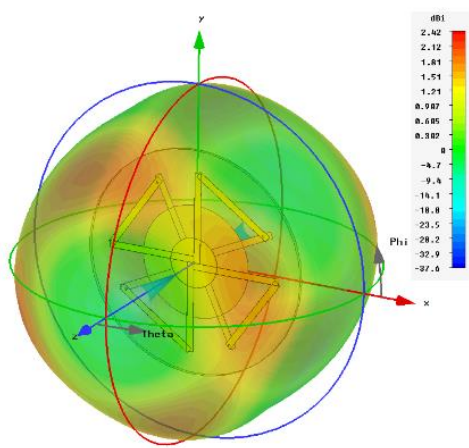

(b)

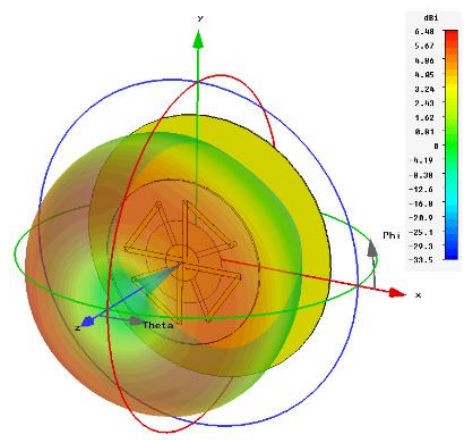

(d)

Figure 12. 3D radiation pattern for (a) 3-blade cloverleaf antenna, (b) 4-blade cloverleaf antenna,

(c) 3-blade cloverleaf antenna with reflector and (b) 4-blade cloverleaf antenna with reflector

\section{CONCLUSION}

Two types of cloverleaf antenna design at $2.45 \mathrm{GHz}$ cloverleaf antenna for unmanned aerial vehicle (UAV) are proposed. Those two antenna designs are 3-blade omni-directional cloverleaf antenna and 4-blade omni-directional cloverleaf antenna. Furthermore, the proposed antennas are then being incorporated with reflector in order to achieve higher gain and directional radiation pattern. The antenna operates at the frequency range of $2.4 \mathrm{GHz}$ to $2.50 \mathrm{GHz}$ with return loss less than $-10 \mathrm{~dB}$. The low profile structure, high gain, and directional radiation pattern of the proposed antenna makes it compact and suitable to be deployed on an UAV for reliable communication between UAV and ground station. 


\section{ACKNOWLEDGEMENTS}

This work was supported by Ministry of Higher Education (MOHE), Faculty of Engineering Technology, Research Center of Applied Electromagnetics, Research Management Centre, Universiti Tun Hussein Onn Malaysia (UTHM) under Grant (Vote No: FRGS 1619 / FRGS 1614 / GPPS U735).

\section{REFERENCES}

[1] John P. Stang, Steven Weiss, "A Compact CPW-Fed Microstrip Patch Antenna Array for Unmanned Miniature Aerial Vehicle Radar," IEEE Antennas and Propagation Society International Symposium (AP-S), USA, July 2008.

[2] L.Y. Ilnitsky, O.A. Shcherbyna, I.I. Mykhalchuk, "Ring antenna system of polarimeter for UAV," 2015 IEEE International Conference Actual Problems of Unmanned Aerial Vehicles Developments (APUAVD), pp. 210-214, 2015.

[3] Diana Verónica Navarro-Méndez, Hon Ching Moy-Li, Luis Fernando Carrrera-Suárez, Miguel Ferrando-Bataller, Mariano Baquero-Escudero, "Antenna arrays for unmanned aerial vehicle," 9th European Conference on Antennas and Propagation (EuCAP), pp. 1-5, 2015.

[4] D. Subramaniam, M. Jusoh, T. Sabapathy, M. N. Osman, M. R. Kamarudin, R. R. Othman, M. R. Awal, "A compact high-gain parasitic patch antenna with electronic beam-switching," Indonesian Journal of Electrical Engineering and Computer Science, Vol 13, No 2, pp. 551-555, 2019.

[5] Ali Khalid Jassim, Raad H. Thaher, "Enhancement gain of broadband elliptical microstrip patch array antenna with mutual coupling for wireless communication," Indonesian Journal of Electrical Engineering and Computer Science, Vol. 13, No. 1, pp. 217-225, 2019.

[6] Zheng Gong, Shangkun Ge, Tongfeng Guo, Qingfeng Zhang, Yifan Chen, "A compact planar 24GHz quasi-Yagi antenna for unmanned aerial vehicle radar applications," 2017 IEEE International Conference on Computational Electromagnetics (ICCEM), pp. 104-105, 2017.

[7] Sungjoon Yoon, Jinpil Tak, Jaehoon Choi, Young-Mi Park, "Conformal monopolar antenna for UAV applications," 2017 IEEE International Symposium on Antennas and Propagation \& USNC/URSI National Radio Science Meeting, pp. 517-518, 2017.

[8] Peter Knott, Claudius Locker, "Design of a Structure Integrated Antenna for a Small Unmanned Aerial Vehicle," 3rd European Conference on Antennas and Propagation (EuCAP), Germany, June 2009.

[9] Fabio Paonessa, Giuseppe Virone, Pietro Bolli, Andrea M. Lingua, "UAV-based antenna measurements: Scan strategies," 2017 11th European Conference on Antennas and Propagation (EUCAP), pp. 1303-1305, 2017.

[10] Sharif Ozman, Ajmal Hussain Shah, Sardar Ali, Sathish Kumar Selvaperumal, Veeraiyah Thangasamy, "Gain Enhancement of Axial Mode Helical Antenna for UAV Applications," 2015 6th International Conference on Intelligent Systems, Modelling and Simulation, pp. 237-241, 2015.

[11] H. Jairam, "Novel Blade Antenna Using Microstrip Patch Elements," 19th European Microwave Conference, United Kingdom, Sept. 1989.

[12] Ajay Kumar Sharma, B.V.R Reddy, Ashok Mittal, "Fan Blade Shaped Slotted Patch Antenna for Wideband Circular Polarization," International Conference on Computer and Computational Sciences, (ICCCS), India, 2015.

[13] Muslim Mahardika, Enggar Yudha Prasetyo, "UAV Long Range Surveillance System Based on BiQuad Antenna for the Ground Control Station," IEEE Student Conference on Research \&Development (SCOReD), Malaysia, 2016.

[14] Karina Vieira Hoel1, Stein Kristoffersen, Jonas Moen, Gjermund Holm, Tor Sverre Lande, "Characterization of a 3D Printed Wideband Waveguide and Horn Antenna Structure Embedded in a UAV Wing," 10th European Conference on Antennas and Propagation (EuCAP), Switzerland, April 2016.

[15] D. Kang, J. Tak and J. Choi, "Wideband low-profile planar square segmented loop antenna for UAV applications," Electronics Letters, Vol. 52(22), 2016.

[16] Fabrizio Trotta, Antonio Manna, Luca Scorrano, "A small lightweight wideband printed dipole for UAV applications," 2014 IEEE Antennas and Propagation Society International Symposium (APSURSI), pp. 1582-1583, 2014.

[17] Luca Scorrano, Antonio Manna, Daniele Spaziani, Fabrizio Trotta, Pasquale Naglieri, Mauro Ferrari, "A novel ultra-wideband UHF low-profile monopole for UAV platforms," 2015 International Symposium on Antennas and Propagation (ISAP), pp. 1-3, 2015.

\section{BIOGRAPHIES OF AUTHORS}

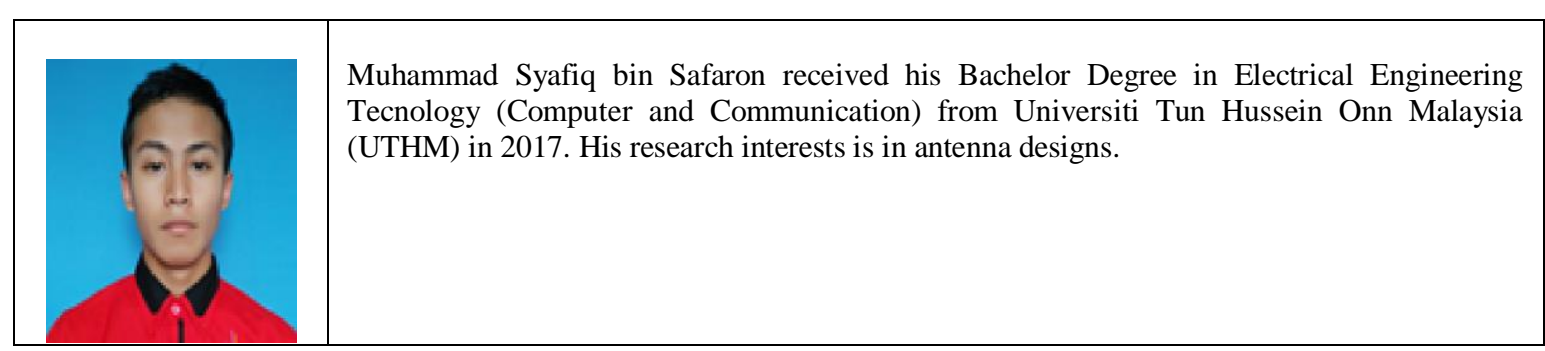

Indonesian J Elec Eng \& Comp Sci, Vol. 14, No. 2, May 2019 : 773 - 779 


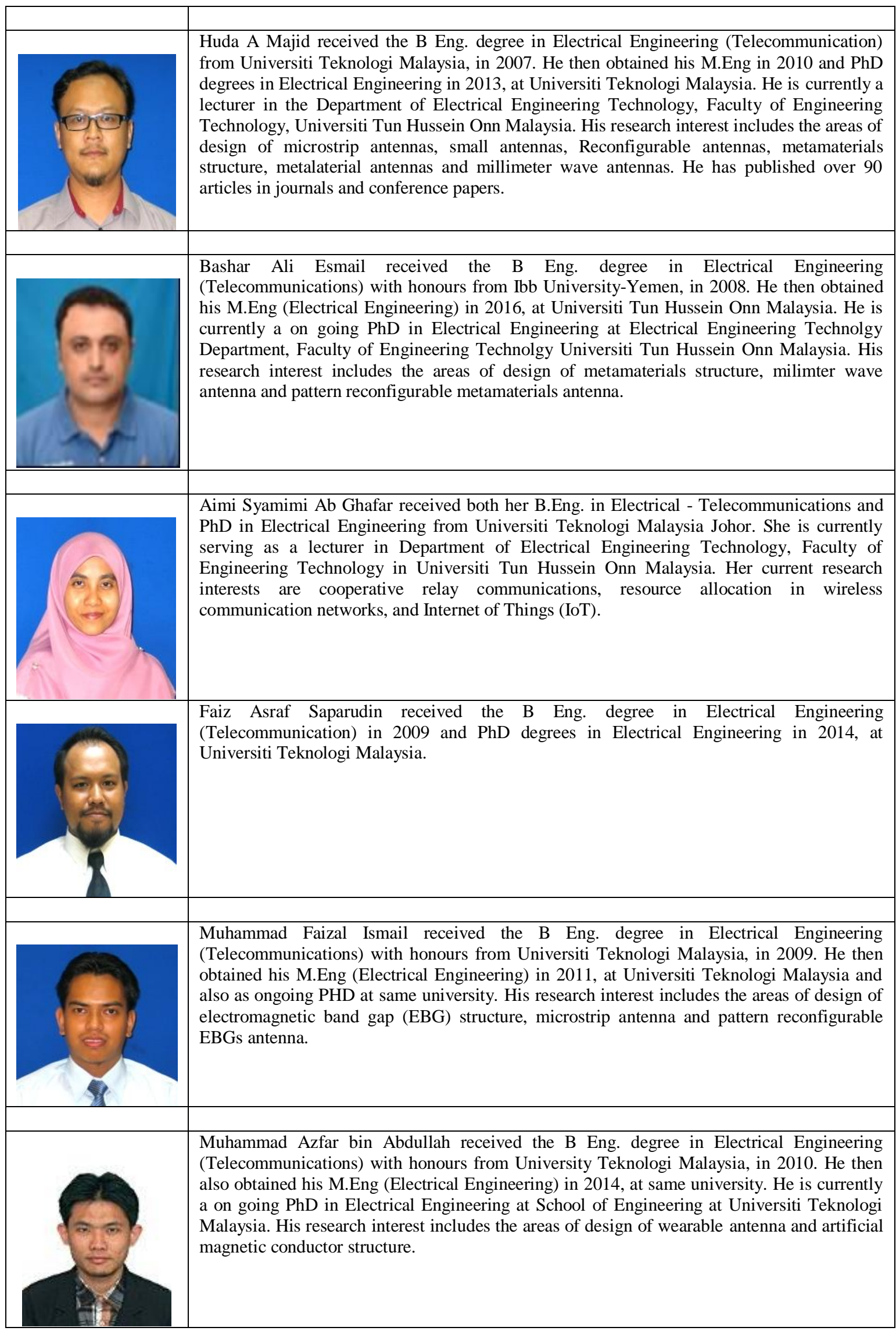

